\title{
Recent Advances in the Catalytic Applications of Lanthanide-Oxo Clusters
}

\author{
Weiming Huang ${ }^{1}$, Qingxin Liu ${ }^{1}$, Wanmin Chen ${ }^{1}$, Min Feng ${ }^{1, *}$ and Zhiping Zheng ${ }^{1,2, *}$ \\ 1 Department of Chemistry, Southern University of Science and Technology, Shenzhen 518055, China; \\ 11930109@mail.sustech.edu.cn (W.H.); 11930572@mail.sustech.edu.cn (Q.L.); chenwm@sustech.edu.cn (W.C.) \\ 2 Shenzhen Grubbs Institute, Southern University of Science and Technology, Shenzhen 518055, China \\ * Correspondence: fengm@sustech.edu.cn (M.F.); zhengzp@sustech.edu.cn (Z.Z.)
}

check for updates

Citation: Huang, W.; Liu, Q.; Chen, W.; Feng, M.; Zheng, Z. Recent Advances in the Catalytic

Applications of Lanthanide-Oxo Clusters. Magnetochemistry 2021, 7, 161. https://doi.org/10.3390/ magnetochemistry7120161

Academic Editors: Catherine P. Raptopoulou, Salah Massoud and Fabrice Pointillart

Received: 2 November 2021 Accepted: 15 December 2021 Published: 20 December 2021

Publisher's Note: MDPI stays neutral with regard to jurisdictional claims in published maps and institutional affiliations.

Copyright: (c) 2021 by the authors. Licensee MDPI, Basel, Switzerland. This article is an open access article distributed under the terms and conditions of the Creative Commons Attribution (CC BY) license (https:// creativecommons.org/licenses/by/ $4.0 /)$.

\begin{abstract}
Lanthanide-oxo/hydroxo clusters (LOCs) in this mini-review refer to polynuclear complexes featuring a polyhedral metal-oxo/hydroxo cluster core of lanthanide ions exclusively or with coexisting $3 d$ metal ions. We summarize herein the recent works using this unique family of cluster complexes for catalysis; this aspect of research stands in stark contrast to their extensively studied synthetic and structural chemistry as well as the much-researched magnetic properties. Following a brief introduction of the synthetic strategies for these clusters, pertinent results from available literature reports are surveyed and discussed according to the types of catalyzed reactions. Particular attention was paid to the selection of a cluster catalyst for a specific type of reactions as well as the corresponding reaction mechanism. To the end, the advantages and challenges in utilizing LOCs as multifunctional catalysts are summarized, and possible future research directions are proposed.
\end{abstract}

Keywords: lanthanide; clusters; synthesis; catalysis

\section{Introduction}

Polynuclear lanthanide ( $\mathrm{Ln}$ ) complexes are of interest because of their attractive molecular structures, interesting luminescence and magnetic properties, and potentially useful applications [1-3]. Starting from the late 1990s, a unique class of polynuclear Ln complexes characterized with well-defined polyhedral Ln-oxo/hydroxo cluster (LOC) core motifs appeared in the literature [4,5]. Reports of heterometallic LOCs with coexisting Ln and $3 d$ metal ions followed shortly after [6,7]. In the past decades, research on LOCs has been primarily concerned with the development of high-nuclearity Gd-containing clusters because of their potential applications for magnetic refrigeration, which is an energy-efficient and environment-friendly cooling technology [8]. Studies have shown that $\mathrm{Gd}^{3+}$-containing clusters possess high magnetic density and weak magnetic exchange coupling and are ideal for achieving large magnetocaloric effects [9]. Not surprisingly, most LOCs have been researched for the purpose of identifying materials with promising magnetic properties for cooling applications [8,10,11].

In contrast with the flourishing research on the magnetic properties of LOCs, the unique catalytic properties of such clusters due largely to the Lewis acidity of Ln ions are largely overlooked, although catalytically interesting Ln-containing complexes [12], coordination polymers (CPs) [13], metal-organic frameworks (MOFs) [14], perovskites [15], and nanoparticles [16] have been reported. A number of obstacles may be responsible for the lack of catalytic studies using LOCs. First of all, despite an increasing number of LOCs appearing in the literature, systematic and reproducible synthesis of LOCs remains a great challenge. Second, little is known about the solution behavior or stability of LOCs; maintaining their structural integrity in solution is essential for their catalytic applications and more fundamentally for the understanding of the catalytic mechanism. Lastly, correlation of their catalytic performance with their molecular structures is a challenge due to the presence of multiple metal sites within an LOC. Nevertheless, LOCs promise catalytic 
potentials due to the unique electronic properties inherent to Ln ions. Adding to their traits propitious to catalysis is the rich redox chemistry of a number of Ln ions $\left(\mathrm{Ce}^{4+} / \mathrm{Ce}^{3+}\right.$, $\left.\mathrm{Sm}^{3+} / \mathrm{Sm}^{2+}, \mathrm{Eu}^{3+} / \mathrm{Eu}^{2+}\right)$ [17] as well as the flexible coordination characteristics due to the primarily ionic interactions between an Ln ion and a ligand [18]. Moreover, the presence of multiple adjacent metal sites offers the possibility for synergistic catalysis; this structural feature is unavailable in mononuclear or low-nuclearity Ln complexes or Ln MOFs. With the recognition of the unique electronic and structural features of LOCs, a small number of groups have conducted research on the catalytic properties of LOCs. These exciting results are surveyed in this mini-review.

Herein, following a brief introduction of the synthetic strategies and the characterization developments, catalytically useful LOCs available in the literature are surveyed according to the types of catalyzed reactions. Particular attention is paid to the selection of an LOC for a target reaction. A brief summary is provided toward the end, together with some personal thoughts regarding where future research in this vein may take us.

\section{Developments on Synthetic Strategies and Characterizations}

\subsection{Synthetic Strategies}

Since the first report in 1994 of an unexpected LOC featuring a cubane-like core of $\left[\mathrm{Ln}_{4}\left(\mu_{3}-\mathrm{OH}\right)_{4}\right]^{8+}$ (Figure 1a) [4], a large number of LOCs have appeared in the literature. This synthetic advance can be attributed to the development of the now well-adopted approach of ligand-controlled Ln hydrolysis, which was developed first by our group [19]. In such an approach, certain judiciously selected organic ligands are used to occupy part of the Ln coordination sphere, leaving only a small number of coordination sites for aqua coordination. As such, the degree of hydrolysis is limited, producing compositionally and structurally definitive LOCs (Figure 1b); without such a control, only intractable polymeric Ln oxides and oxo/hydroxides are obtained.

Additionally, the anion template is another approach for obtaining sophisticated LOCs. A particularly significant aspect in the synthesis of LOCs is the participation of smallunit anions that serve to template the self-assembly of higher-nuclearity LOCs wherein structurally well-defined subunits are frequently identified [20]. For example, wheel-like LOCs composed of $4\left(\mathbf{L n}_{12}\right)$ and $5\left(\mathbf{L n}_{15}\right)$ vertex-sharing $\left[\operatorname{Ln}_{4}\left(\mu_{3}-\mathrm{OH}\right)_{4}\right]^{8+}$ subunits were obtained with the assistance of $\mathrm{I}^{-}$and $\mathrm{Cl}^{-} / \mathrm{Br}^{-}$, respectively (Figure 1c) [21]. Using $\mathrm{CO}_{3}{ }^{2-}$ in a similar capacity led to the formation of the hexagonal wheel structure of $\mathbf{L n}_{18}$ (Figure 1c) [22].

a

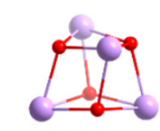

$\operatorname{Ln}_{4}$

C

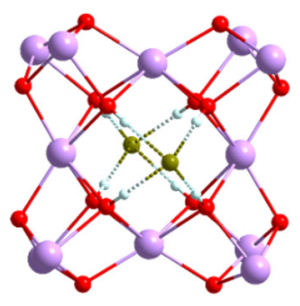

$\mathrm{Ln}_{12}$

$\mathrm{b}$
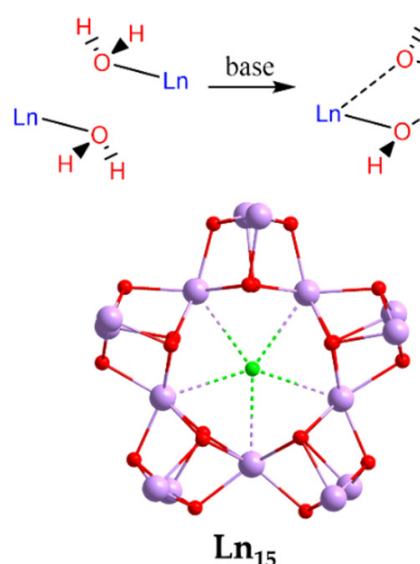
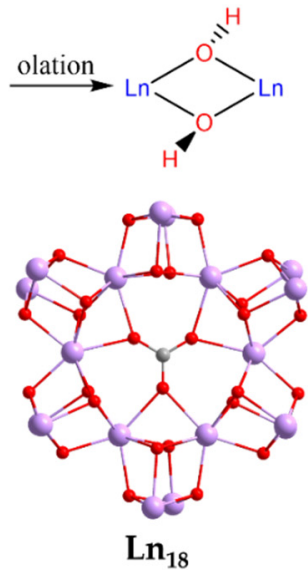

Figure 1. (a) The structures of building units $\left[\operatorname{Ln}_{4}\left(\mu_{3}-\mathrm{OH}\right)_{4}\right]^{8+}$. (b) The key step of ligand-controlled hydrolysis of $\mathrm{Ln}^{3+}$ ions [19]. (c) Templated anions $\mathrm{I}^{-}, \mathrm{Cl}^{-}$, and $\mathrm{CO}_{3}{ }^{2-}$ in $\mathbf{L n}_{\mathbf{1 2}}, \mathbf{L n}_{\mathbf{1 5}}$, and $\mathbf{L} \mathbf{n}_{\mathbf{1 8}}$, respectively. Color legends: Ln, lavender; $\mathrm{O}$, red; I, dark yellow; $\mathrm{H}$, light turquoise; $\mathrm{Cl}$, green; $\mathrm{C}$, gray [21,22]. 
The successful application of the ligand-controlled hydrolysis in combination with anion templates has led to the production of LOCs with diverse and pleasing molecular structures that are otherwise synthetically elusive or impossible. The use of other types of hydrolysis-limiting ligands, including metal complexes as ligands or the so-called metalloligand [23] and mixtures of ligands [24] has also been reported. Moreover, the use of a combination of different anions as mixed templates has led to the production of gigantic and structurally sophisticated LOCs [25].

\subsection{Characterizations}

Techniques typically used for the characterization of crystalline compounds, including single-crystal and powder X-ray diffraction, thermogravimetric analysis, BrunauerEmmett-Teller (BET) surface area measurement, and infrared spectroscopy, have been used in most of the LOC studies. As catalytic applications in solution, however, understanding the solution behavior or stability of LOCs is critical to correlate any observed catalytic properties with their molecular structures. As most of these LOCs are ionic compounds composed of a polynuclear cationic cluster and counteranions, dissociation into the component ions is suspected in solution. Maintaining the structural integrity of the cationic cluster unit is critical, as otherwise, metal-containing subunits may be produced due to the decomposition of the original cluster. In other words, a "solution-stable" cluster should be one that keeps the same cationic cluster structure as in its crystalline state. Therefore, the applied solvent should be carefully optimized to obtain this stability, which can be verified by using spectroscopic and electron microscopic techniques. For example, a single peak shown in the MALDI-TOF-MS of the $\mathbf{N i}_{36} \mathbf{G d}_{\mathbf{1 0 2}}$ cluster in methanol corresponds to the unaltered cationic cluster complex unit; the broadness is due to the distribution of the large number of atoms with isotopes (Figure 2a) [26]. In another example, imaging a sample prepared by dissolving the $\mathbf{G d}_{\mathbf{1 4 0}}$ cluster in ethanol using high-angle annular dark-field scanning transmission electron microscopy (HAADF-STEM) revealed the overall wheel-like molecular structure of the cluster (Figure 2b) [27]. Direct visualization of the nanoscopic structure of a cluster provides the most convincing evidence for its solution stability. Other techniques have provided additional supporting evidence. For example, dynamic light-scattering (DLS) measurement produced a hydrodynamic diameter that matches with its molecular structure (Figure 2c) [27]. During catalysis, techniques such as extended X-ray-absorption final structure (EXAFS) and X-ray absorption near-edge structure (XANES) have been used to monitor the stability of the cluster in situ (vide infra).
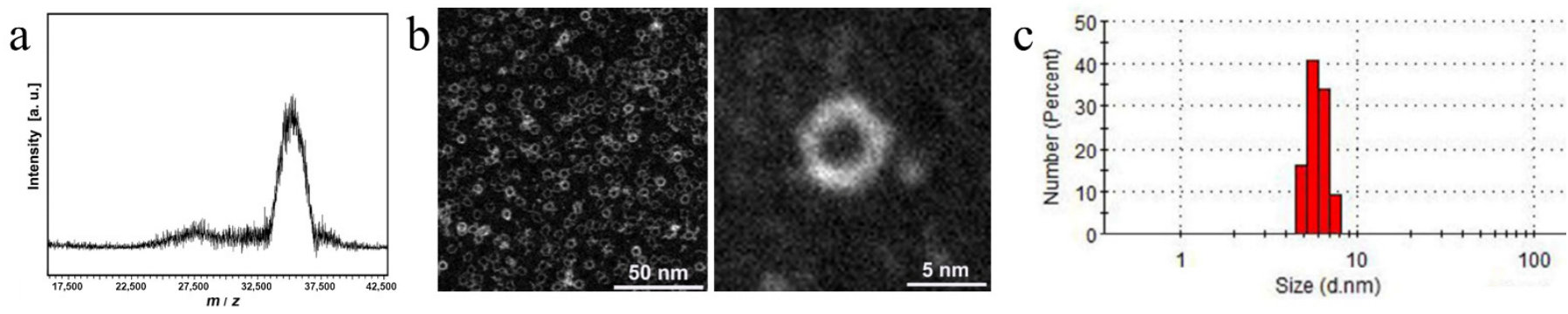

Figure 2. (a) MALDI-TOF-MS of $\mathbf{N i}_{\mathbf{3 6}} \mathrm{Gd}_{\mathbf{1 0 2}}$ in methanol [26]. (b) HAADF-STEM images of Gd $\mathbf{1 4 0}_{\mathbf{1 4 0}}$ [27]. (c) DLS measurement result of $\mathbf{G d}_{\mathbf{1 4 0}}$ in water solution [27]. Reprinted with permission from Refs. [26,27]. Copyright 2020, 2017 American Chemical Society.

\section{LOCs as Catalysts for $\mathrm{CO}_{2}$ Transformation into Value-Added Products}

$\mathrm{CO}_{2}$, as the stable combustion product and greenhouse gas, is one of the main causes of global warming. Finding an economical and efficient carbon cycle process involving $\mathrm{CO}_{2}$ conversion could relieve the accumulation of $\mathrm{CO}_{2}$ in nature. 


\subsection{Catalytic Cycloaddition of $\mathrm{CO}_{2}$ and Epoxides}

Along this line of thought, one of the reactions receiving arguably the most attention is the production of cyclic carbonates, which is a valuable stock for the preparation of polymeric materials, by the catalytic reaction of $\mathrm{CO}_{2}$ with epoxides [28-30]. The commonly accepted mechanism involves the activation of both an epoxide and $\mathrm{CO}_{2}$. The hard Lewis acidity and oxophilicity of $\mathrm{Ln}^{3+}$ are particularly attractive for the activation of epoxide by way of strong Ln-O coordination; thus, a variety of catalysts including those Ln-based have been developed for this reaction [30-32].

LOCs have also been explored in this capacity. For example, Zhang et al. reported two series of heterometallic LOCs, namely $\mathrm{Ln}_{2} \mathrm{Zn}_{2}\left(\mu_{3}-\mathrm{OH}\right)_{2}\left(\mathrm{~L}^{1}\right)_{4}\left(\mathrm{NO}_{3}\right)_{4}\left(\mathbf{L n}_{2} \mathbf{Z n}_{2}, \mathrm{Ln}=\mathrm{Eu}, \mathrm{Tb}\right.$, $\mathrm{Er}, \mathrm{Yb}, \mathrm{Nd}, \mathrm{HL}^{1}=$ Methyl-3-methoxysalicylate, Figure 3$)$ and $\mathrm{Ln}_{2} \mathrm{Zn}_{4}\left(\mu_{3}-\mathrm{OH}\right)_{2}\left(\mathrm{~L}^{1}\right)_{4}(\mathrm{OAc})_{6}\left(\mathrm{NO}_{3}\right)_{2}$ $\left(\mathbf{L n}_{2} \mathbf{Z n} \mathbf{n}_{4}, \mathbf{L n}=\mathrm{Tb}, \mathrm{Nd}\right)$, and studied their applications for the $\mathrm{CO}_{2}$ and epoxide cycloaddition (Figure 4) [33]. All these cluster complexes have been shown to heterogeneously catalyze the reaction with $\mathrm{Tb}_{2} \mathrm{Zn}_{2}$ being most effective, producing a turnover number (TON) of 9260 and a turnover frequency (TOF) of $661 \mathrm{~h}^{-1}$ in a $12 \mathrm{~h}$ reaction. This performance is significantly better than that of using other Ln-based catalysts under similar reaction conditions [33,34]. Moreover, high tolerance for a wide variety of epoxides was also demonstrated. The authors rationalized the high activity under the mild conditions using the bimetallic activation of both substrates (Figure 4c): Both $\mathrm{CO}_{2}$ and the epoxide are activated upon coordination by the polynuclear cluster core. The intramolecular attack of $\mathrm{CO}_{2}$ by the ring-opened epoxide $\mathrm{O}$ afforded an alcoholate intermediate, leading eventually to the carbonate product. What distinguishes such a heterometallic catalyst from homometallic ones is that the metal with stronger Lewis acidity, Ln in this case, would enhance epoxide coordination, while the other metal center would activate the $\mathrm{CO}_{2}$ [35]. This selective activation might enhance the chance of these two different reactant molecules being activated nearby, which would accelerate the interaction between them, instead of the same reactants being activated closely. Moreover, the establishment of the heterometallic activation arrangement could be easily realized through the unique polynuclear LOCs.<smiles>COC(=O)c1cccc(OC)c1O</smiles>

Methyl-3-methoxysalicylate $\left(\mathrm{HL}^{1}\right)$

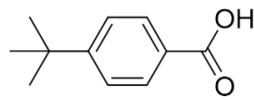

4-tert-Butylbenzoic acid $\left(H L^{4}\right)$<smiles>Cc1nnc(S)s1</smiles>

$\mathrm{N}-\mathrm{N}$

$\left(\mathrm{HL}^{2}\right)$<smiles>O=C(O)CNCC(=O)O</smiles>

Iminodiacetic acid $\left(\mathrm{H}_{2} \mathrm{~L}^{5}\right)$<smiles>CC(CO)(CO)C(=O)O</smiles>

2,2-Dimethylol propionic acid $\left(\mathrm{H}_{3} \mathrm{~L}^{3}\right)$

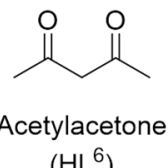

$\left(\mathrm{HL}^{6}\right)$

Figure 3. The structural formula and abbreviations of the hydrolysis-controlling ligands used in this review.

\subsection{Catalytic Reduction of $\mathrm{CO}_{2}$}

In addition to the above chemical fixation of $\mathrm{CO}_{2}$, catalytic reductions of $\mathrm{CO}_{2}$ have also been extensively explored to produce value-added products including $\mathrm{CO}, \mathrm{HCHO}$, $\mathrm{HCOOH}, \mathrm{CH}_{3} \mathrm{OH}$, and $\mathrm{CH}_{4}$ [36]. Various catalysts have been developed for photochemical and electrochemical $\mathrm{CO}_{2}$ reduction [37]. The non-noble metal nickel-based catalysts possess high CO selectivity [38]; therefore, LOCs with abundant bare Ni centers make it a promising candidate for $\mathrm{CO}$ production. 

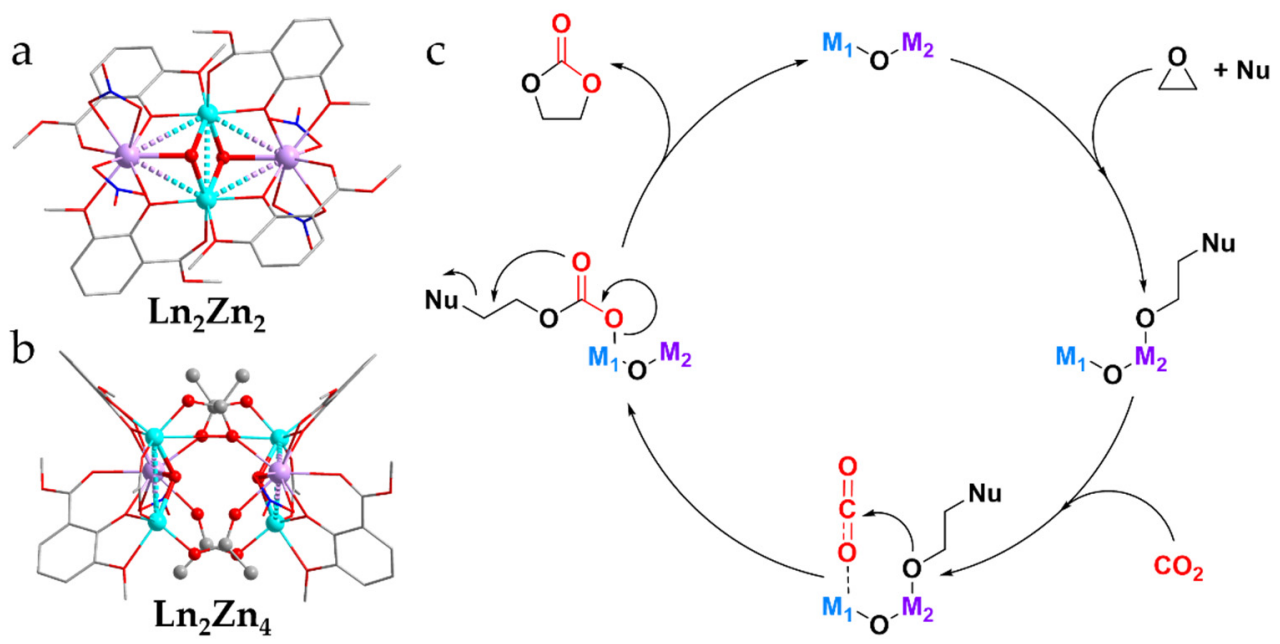

Figure 4. (a) The structure of cluster $\mathbf{L n}_{\mathbf{2}} \mathbf{Z n}_{\mathbf{2}}$. (b) The butterfly-shaped structure of cluster $\mathbf{L n}_{\mathbf{2}} \mathbf{Z n}_{\mathbf{4}}$. (c) Bimetallic pathway with simultaneous activation of epoxide and $\mathrm{CO}_{2}$ on the adjacent metal centers. Color legends: Ln, lavender; Zn, turquoise; O, red; C, gray; N, blue [33].

In this vein, Zheng et al. have reported a 138-metal LOC $\left[\mathrm{Ni}_{36} \mathrm{Gd}_{102}\left(\mu_{3}-\mathrm{OH}\right)_{132}\left(\mathrm{~L}^{2}\right)_{18}\left(\mathrm{~L}^{3}\right)\right.$ $\left.{ }_{18}\left(\mathrm{H}_{2} \mathrm{~L}^{3}\right)_{24}(\mathrm{OAc})_{84}\left(\mathrm{SO}_{4}\right)_{18}\left(\mathrm{NO}_{3}\right)_{18}\left(\mathrm{H}_{2} \mathrm{O}\right)_{30}\right] \mathrm{Br}_{6} \cdot\left(\mathrm{NO}_{3}\right)_{6} \cdot\left(\mathrm{H}_{2} \mathrm{O}\right)_{x} \cdot\left(\mathrm{CH}_{3} \mathrm{OH}\right)_{\mathrm{y}}\left(\mathbf{N i}_{36} \mathbf{G d}_{\mathbf{1 0 2}}, \mathrm{HL}^{2}\right.$ $=2$-Mercapto-5-methyl-1,3,4-thiadiazide, $\mathrm{H}_{3} \mathrm{~L}^{3}=2$,2-Dimethylol propionic acid, $\mathrm{x} \approx 130$, $\mathrm{y} \approx 60$ )] and studied its use in the photocatalytic homogeneous $\mathrm{CO}_{2}$ reduction (Figure 5a) [26]. The gigantic "star-of-David"-like cluster (Figure $5 \mathrm{~b}$ ) showed a remarkable reactivity $\left(\mathrm{TON}=29,700(10 \mathrm{~h}), \mathrm{TOF}=1.2 \mathrm{~s}^{-1}\right)$ and selectivity $(90.2 \%)$ for CO formation. This performance is better than most of the photocatalytic homogeneous $\mathrm{CO}_{2}$ reduction catalysts reported [26,39]. The stability of the cluster framework in solution was verified by MALDI-TOF-MS and high-resolution transmission electron microscopy (HR-TEM) results (Figure 5c). The simulation using periodic density functional theory (PDFT) indicated correspondence between the catalytic performance and the strong $\mathrm{CO}_{2}-\mathrm{Ni}$ binding at the initial stage of the reaction. This binding is profoundly influenced by the coordination environment of $\mathrm{Ni}^{2+}$ that is characterized with a number of triply bridging $\mu_{3}-\mathrm{OH}$ groups. Furthermore, a possible hydrogen bond was proposed between the $\mu_{3}-\mathrm{OH}$ group and the $\mathrm{O}$ atom of the $\mathrm{Ni}-\mathrm{CO}_{2}$ intermediate in the optimized structure. Thus, it is reasonable to suspect that the large number of $\mu_{3}-\mathrm{OH}$ groups in this LOC not only helps stabilize the intermediate but also provides protons to promote the breaking of the $\mathrm{C}-\mathrm{O}$ bond in $\mathrm{CO}_{2}$ (Figure $5 \mathrm{~d}$ ). The durability of $\mathbf{N i}_{36} \mathbf{G d}_{\mathbf{1 0 2}}$ was also evaluated. The catalytic performance remained essentially unchanged using samples recovered from the five consecutive runs of experiments. This stable catalytic performance manifests the stability of the cluster species in solution. Under low pressure of $\mathrm{CO}_{2}(0.1 \mathrm{~atm}), \mathbf{N i}_{36} \mathbf{G d}_{102}$ still exhibited decent catalytic activity (TOF $=0.49 \mathrm{~s}^{-1}$ ) and selectivity $(74.4 \%)$ for $\mathrm{CO}$ formation. Previous work suggested that Lewis acidic functionalities help modulate the electronic structure of catalytic $\mathrm{Ni}^{2+}$ centers and thus enhance the photocatalytic activity under low $\mathrm{CO}_{2}$ pressures [40]. In this regard, although $\mathrm{Ln}^{3+}$ was not directly involved in the proposed catalytic cycle, we suspect, based on literature argument, that they are indispensable not only for the stable LOC structure but also for tuning the electronic structure of $\mathrm{Ni}^{2+}$ to modulate the catalytic property. 

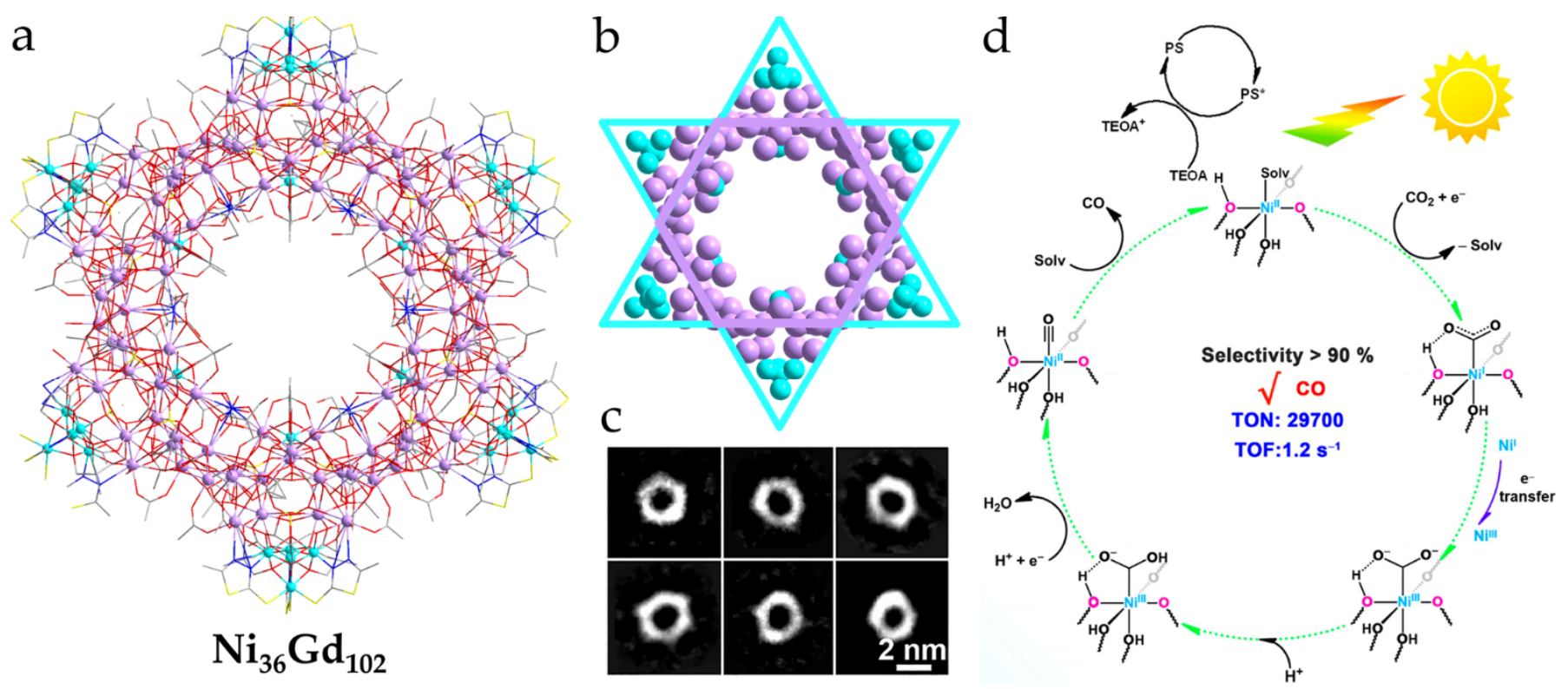

Figure 5. (a) The structures of the $3 d-4 f$ cluster $\mathbf{N i}_{36} \mathbf{G d}_{102}$. (b) The "star-of-David"-like cluster core. (c) The high-resolution TEM images of $\mathbf{N i}_{36} \mathbf{G d}_{\mathbf{1 0 2}}$. (d) The $\mathrm{CO}_{2}$ reduction mechanism. Color legends: Ln, lavender; Ni, turquoise; $\mathrm{O}$, red; $\mathrm{C}$, gray; N, blue; S, yellow. Reprinted with permission from Ref. [26]. Copyright 2020 American Chemical Society.

\section{LOCs as Electrochemical Catalysts for Water Splitting}

Water splitting is the conversion of water molecules into $\mathrm{H}_{2}$ and $\mathrm{O}_{2}$. This reaction is of significant ramifications in our effort to address current and future energy and environmental challenges.

\subsection{LOCs as Homogeneous Catalysts for Water Oxidation}

Being a half reaction in the overall water splitting scheme, the oxidation of $\mathrm{H}_{2} \mathrm{O}$ to $\mathrm{O}_{2}$ involves the concerted removal of four protons and four electrons from two water molecules [41]. Thus, this reaction is both energetically demanding and kinetically limited. Catalysts based on both precious and earth-abundant metals have been investigated for water oxidation. Although some Ru-based catalysts produced excellent catalytic results [42], any industrial-scale applications is not yet forthcoming due to the scarcity of the precious metal and associated high costs [43]. Inspired by the structure of cuboidal $\mathrm{CaMn}_{4} \mathrm{O}_{5}-$ the oxygen-evolving center (OEC) of photosystem II-earth-abundant metal-oxo species have been investigated as potential catalysts for water oxidation. Recently, Yao et al. reported that the $\mathrm{Ca}^{2+}$ in $\mathrm{CaMn}_{4} \mathrm{O}_{5}$ structure can be replaced by $\mathrm{Ln}^{3+}$, providing a robust mimic for the structure-function correlation study in the OEC. The impact of the Lewis acidity of the redox-inactive ions $\left(\mathrm{Ca}^{2+}, \mathrm{Ln}^{3+}\right)$ on the $\mathrm{Mn}$ redox potentials were studied by comparing the $\mathrm{Mn}$ redox potentials in different analogues containing different $\mathrm{Ln}^{3+}$ ions with different Lewis acidity. Therefore, LOCs could provide an analytical platform for structure-function correlation studies by investigating the properties of isomorphous LOCs containing different $\mathrm{Ln}^{3+}$ ions with different properties such as Lewis acidity, ionic size, redox properties, and magnetic properties.

Recently, Chen et al. isolated three LOCs $\left[\mathrm{Ln}_{36} \mathrm{Co}_{12}\left(\mu_{4}-\mathrm{O}\right)_{6}\left(\mu_{3}-\mathrm{OH}\right)_{84}(\mathrm{OAc})_{18}(\mathrm{Cl})_{2}\left(\mathrm{NO}_{3}\right)\right]^{33+}$ $\left(\mathbf{L a}_{36} \mathrm{Co}_{12}, \mathrm{Ln}=\mathrm{Eu}, \mathrm{Gd}\right.$, and Dy) (Figure 6a) featuring 22 heterometallic cubane unis of $\left[\mathrm{Ln}_{3} \mathrm{Co}\left(\mu_{3}-\mathrm{OH}\right)_{4}\right]^{7+}$ in a tubular core structure [44]. At $\mathrm{pH}=5.8, \mathbf{E u}_{36} \mathrm{Co}_{12}$ exhibited the highest activity for homogeneous water oxidation, producing a TOF of $1.5 \mathrm{~s}^{-1}$ at $1.8 \mathrm{~V}$ (vs. NHE). Comparative studies using $\mathrm{Eu}_{36} \mathrm{Co}_{12}$ against $\mathrm{Co}(\mathrm{Ac})_{2}$ and $\mathrm{Eu}\left(\mathrm{NO}_{3}\right)_{3}$ revealed a significant difference in the catalytic performance; the decreasing activity order of $\mathbf{E u}_{36} \mathbf{C o}_{12}$ $>\mathrm{Co}(\mathrm{Ac})_{2}>\mathrm{Eu}\left(\mathrm{NO}_{3}\right)_{3}$ indicates that the catalytic activity origin of $\mathbf{E u}_{36} \mathbf{C o}_{12}$ is not simply individual behaviors of $\mathrm{Co}^{2+}$ and $\mathrm{Eu}^{3+}$ ions but a synergy between them in the heterometal- 
lic LOC. The overpotential of $1 \mathrm{~mA} \mathrm{~cm}{ }^{-2}$ observed for $\mathbf{E u}_{36} \mathrm{Co}_{12}$ is $700 \mathrm{mV}$, which is close to the cluster-based homogeneous electrocatalysts. Of particular note is the unmitigated performance of $\mathbf{E u}_{36} \mathbf{C o}_{12}$ after $10 \mathrm{~h}$ of reaction, suggesting its stability in solution. Providing support of its stability are results from the comparative studies using DLS, XANES, and EXAFS on samples before and after catalytic studies. Electrochemical measurements by differential pulse voltammetry (DPV) and cyclic voltammetry (CV) under different $\mathrm{pH}$ conditions were used to rationalize the high electrocatalytic activities, and a possible mechanism for the observed water oxidation was proposed (Figure $6 b$ ), wherein the synergy between $\mathrm{Eu}^{3+}$ and $\mathrm{Co}^{2+}$ ions was elaborated in terms of the cooperative aqua coordination on both $\mathrm{Eu}^{3+}$ and $\mathrm{Co}^{2+}$ sites. The one on the $\mathrm{Co}^{2+}$ site undergoes dehydrogenation to produce $\mathrm{Co}^{\mathrm{IV}}=\mathrm{O}$. Then, the aqua ligand on the $\mathrm{Eu}^{3+}$ site dehydrogenates to afford the $\mathrm{Co}^{3+}$-hydroperoxyl-Eu ${ }^{3+}$ intermediate. Finally, one molecule of $\mathrm{O}_{2}$ is released upon decomposition of this intermediate, and the re-capping of one aqua ligand onto both metal sites completes the catalytic cycle. As suggested by this study, heterometalic LOCs may represent a new family of water oxidation catalysts due to the synergy between the different metal sites.

a

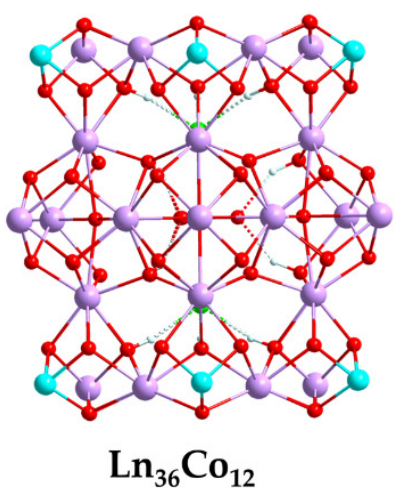

$\mathrm{b}$

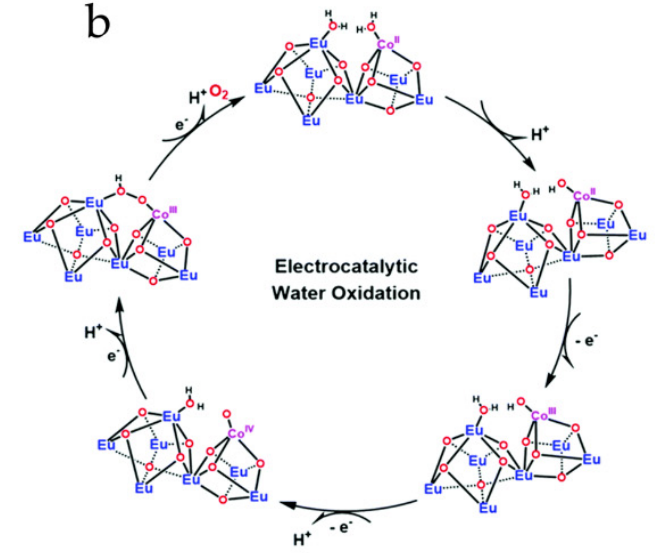

C

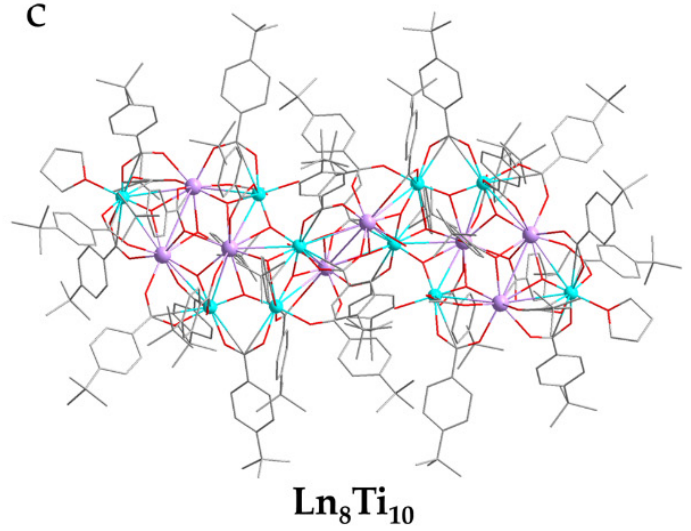

Figure 6. (a) The structure of $\mathbf{L n}_{36} \mathbf{C o}_{12}$ cluster core. (b) The proposed mechanism for water oxidation [44]. (c) The structure of $\mathbf{L n}_{\mathbf{8}} \mathbf{T i}_{10}$ [45]. Color legends: Ln, lavender; $\mathrm{Co}$ and Ti, turquoise; O, red; C, gray; N, blue; Cl, green. Reprinted with permission from Ref. [44]. Copyright 2021 Royal Society of Chemistry.

\subsection{LOCs as Heterogeneous Catalysts for Water Oxidation}

Since the report by Fujishima and Honda in 1972 of the photoelectrochemical catalytic activity of $\mathrm{Pt} / \mathrm{TiO}_{2}$ for water splitting [46], extensive research has been devoted to the research of Ti-containing catalysts/materials [47-49]. However, $\mathrm{TiO}_{2}$-based semiconductors are with wide bandgaps, and the corresponding photocatalytic reactions utilize only an ultraviolet portion of the solar energy [50]. Bandgap engineering can be achieved with the doping of an extraneous metal to expand the light window so that the full wavelength range of sunlight may be used, and the photocatalysis efficiency can be enhanced [50]. In this regard, a Ti-containing LOC may be viewed alternatively as an Ln-doped Ti-oxo semiconductor with a definitive structure and already tuned bandgap.

In a recent report, Kong et al. prepared three isomorphous Ti-containing LOCs of the general formula $\left[\mathrm{Ln}_{8} \mathrm{Ti}_{10}\left(\mu_{3}-\mathrm{O}\right)_{14}\left(\mathrm{~L}^{4}\right)_{34}(\mathrm{OAc})_{2}\left(\mathrm{H}_{2} \mathrm{O}\right)_{4}(\mathrm{THF})_{2}\right] \cdot 2 \mathrm{HL}^{4}\left(\mathbf{L n}_{8} \mathbf{T i}_{10}, \mathbf{L n}=\mathrm{Eu}\right.$, $\mathrm{Sm}, \mathrm{Gd}, \mathrm{HL}^{4}=4$-tert-Butylbenzoic acid) [45] and applied them for photoelectrochemical heterogeneous water oxidation (Figure 6c). Interestingly, with the only difference being the type of $\mathrm{Ln}^{3+}$ in these Ti-containing LOCs, quite different catalytic activities for water oxidation were observed. These results suggest a possible correlation between the catalytic performance and the engineered bandgaps-2.90, 2.95, and $2.96 \mathrm{eV}$ for $\mathbf{E u}_{8} \mathbf{T i}_{\mathbf{1 0}}, \mathbf{S m}_{\mathbf{8}} \mathbf{T i}_{\mathbf{1 0}}$, and $\mathbf{G d}_{\mathbf{8}} \mathbf{T i}_{10}$, respectively. These bandgaps are much lower than that of $\mathrm{TiO}_{2}(3.2 \mathrm{eV})$, which might lead to a red shift of UV-Vis absorption and thus an enhancement of sunlight usage in the catalytic process. The best results (a TON of 7581.0 and a TOF of $2527.0 \mathrm{~h}^{-1}$ ) 
achieved with the use of $\mathbf{E u}_{8} \mathbf{T i}_{10}$ are sizably better than that of anatase, which is one of the classical Ti-based photoelectrochemical catalysts for water oxidation [45]. For $\mathbf{E u}_{8} \mathbf{T i}_{\mathbf{1 0}}$, 16.29 $\mathrm{C}$ of charge was passed under the electrolysis at $1.4 \mathrm{~V}$ (vs. $\mathrm{Ag} / \mathrm{AgCl}$ ) for $3 \mathrm{~h}$, and the measured stable photocurrent densities were $1.43 \mathrm{~mA} \cdot \mathrm{cm}^{-2}$. In analyzing the structure of these Ti-containing LOCs, the authors found that the bridging $\mu_{3}$-O groups are perfectly suited for hydrogen bond formation with $\mathrm{Ti}^{4+}$-bound aqua ligands; such a setup is expected to facilitate $\mathrm{O}-\mathrm{H}$ bond cleavage during the water-oxidation process. In addition, cycle experiments, PXRD, and ICP-MS results verify the durability of $\mathbf{E u}_{8} \mathbf{T i}_{10}$. In this case, LOCs may be a good platform for investigating bandgap engineering of Ti-oxo semiconductors and promoting the all-important water oxidation by photocatalysis.

\subsection{LOCs as Catalysts for Hydrogen Production}

The other half-reaction in the scheme of water splitting is the hydrogen evolution reaction (HER). Numerous semiconductors have been developed for the photocatalytic production of $\mathrm{H}_{2}$, among which CdS has been extensively studied due to its suitable electronic structure for visible light absorption, suitable bandgap, and electronic charge transfer [51]. However, the photocatalytic HER performance of pristine CdS is far from satisfactory, which is primarily due to the rapid recombination of photogenerated charge carriers [51]. As a solution, heterojunctures featuring a cocatalyst loaded onto the surface of a parent CdS have been developed to accelerate the separation and transportation of the photogenerated electrons and holes [52]. Researchers have shown that $\mathrm{Ln}^{3+}$ ions could accelerate the electron transfer from a semiconductor host, but reports of CdS surface modification by $\mathrm{Ln}^{3+}$ are scarce, which is possibly due to the synthetic difficulties associated with the charge difference between the component metal ions and the mismatch of ionic size [53].

In 2018, Chen et al. reported a series of high-nuclearity LOCs of the general formula $\left[\mathrm{Ln}_{52} \mathrm{Ni}_{56-x} \mathrm{Cd}_{\mathrm{x}}\left(\mathrm{L}^{5}\right)_{48}\left(\mu_{3}-\mathrm{OH}\right)_{154}\left(\mathrm{H}_{2} \mathrm{O}\right)_{38}\right]^{18+}\left(\mathbf{L n}_{52} \mathbf{N i}_{56-x} \mathbf{C d}_{x}, \mathrm{Ln}=\mathrm{Eu}, \mathrm{Pr}, \mathrm{Nd}, \mathrm{Gd}\right.$, $\mathrm{H}_{2} \mathrm{~L}^{5}=$ Iminodiacetic acid) by substituting some of the $\mathrm{Ni}^{2+}$ ions in $\mathbf{L n}_{52} \mathbf{N i}_{56}$ with $\mathrm{Cd}^{2+}$ (Figure 7a) [54]. This synthetic goal was achieved by reacting $\mathbf{L n}_{52} \mathbf{N i}_{56}$ with $\mathrm{Cd}\left(\mathrm{NO}_{3}\right)_{2}$ under hydrothermal conditions, and the resulting $\mathbf{L n}_{52} \mathbf{N i}_{56-x} \mathbf{C d}_{x}$ possesses the same fourshell nesting doll-like core structure as its parent $\mathbf{L n}_{52} \mathbf{N i}_{56}$. These Cd-doped heterometallic LOCs can be readily loaded onto the surface of CdS, yielding the corresponding nanocomposites of $\mathbf{L n}_{52} \mathbf{N i}_{56-x} \mathbf{C d}_{x} / \mathrm{CdS}$. These nanocomposites were subsequently applied for heterogeneous photocatalytic HER; the best performance of $25353 \mu \mathrm{mol} \cdot \mathrm{h}^{-1} \cdot \mathrm{g}^{-1}(7.8$ times higher than that of pristine CdS) was achieved with $1.26 \mathrm{wt} \%$ loading of $\mathbf{E u}_{52} \mathbf{N i}_{56-x} \mathbf{C d}$. A mechanism entailing a putative synergy between the different metal centers was proposed (Figure $7 \mathrm{~b}$ ) according to the results of electron paramagnetic resonance (EPR) spectra, UV/Vis diffuse reflectance spectrum (DRS), and Mott-Schottky measurements. The author concluded that charge separation is responsible for the observed difference in catalytic activity between $\mathbf{E u}_{52} \mathbf{N i}_{56-x} \mathrm{Cd}_{x}$ and its cognates of Nd, Gd, and Pr. Specifically, along a path common to all $\mathbf{L n}_{52} \mathbf{N i}_{56-x} \mathrm{Cd}_{x}$ co-catalysts, photoexcited electrons from the surface of CdS could fall into the suitable LUMO energy level of $\mathbf{L n}_{52} \mathbf{N i}_{56-x} \mathbf{C d}_{x}$ for the reduction of protons into hydrogen. However, in the case of $\mathbf{E u}_{52} \mathbf{N i}_{56-x} \mathbf{C d}_{x}$, photoinduced electrons may transfer from the conduction band (CB) of CdS to a suitable electronic level of $\mathrm{Eu}^{3+}$, resulting in the formation of $\mathrm{Eu}^{2+}$ and a secondary catalytic site. This possibility is only available for $\mathbf{E u}_{52} \mathbf{N i}_{56-x} \mathbf{C d}_{x}$ as the energy of the CdS conduction band matches the reduction potential of $\mathrm{Eu}^{3+}$. The ready loading of LOCs onto the surface of CdS offers an easy route to the preparation of semiconducting materials functionalized with different Ln ions. As such, the electronic properties of the resulting catalysts can be tuned for optimal HER catalytic performance. 
a

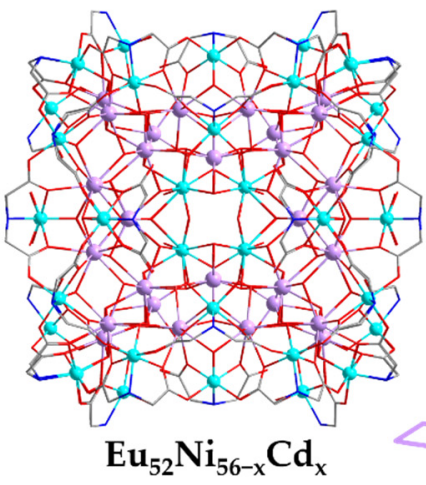

b

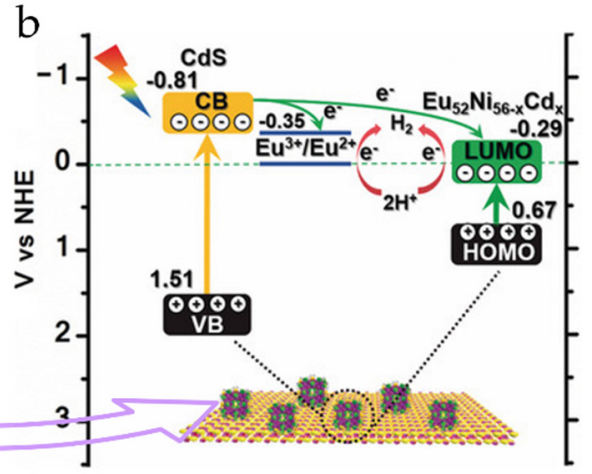

Figure 7. (a) The structure of $\mathbf{E u}_{52} \mathrm{Ni}_{56-x} \mathbf{C d}_{x}$ with $20 \%$ substitution percentage of $\mathrm{Cd}^{2+}$. (b) The mechanism of multipath charge separation in HER. Color legends: Ln, lavender; $\mathrm{Ni}_{0.8} \mathrm{Cd}_{0.2}$, turquoise; $\mathrm{O}$, red; C, gray; N, blue. Reprinted with permission from Ref. [54]. Copyright 2018 Wiley-VCH.

\section{LOCs as Catalysts for Hydroboration Reaction}

Hydroboration of carbonyl-containing compounds is important for obtaining valueadded products from unsaturated organic molecules. Organometallic compounds of lanthanides have been investigated as catalysts for the selective hydroboration of alkenes, carbonyls, imines, and nitriles [55]. However, other types of Ln-based catalysts are still rare. In a recent study, Findlater et al. studied the catalytic applications of a number of LOCs including $\mathrm{La}_{4}\left(\mu_{4}-\mathrm{O}\right)\left(\mathrm{L}^{6}\right)_{10}\left(\mathbf{L a}_{4}, \mathrm{HL}^{6}=\right.$ Acetylacetone $), \mathrm{Ln}_{4}\left(\mu_{3}-\mathrm{OH}\right)_{2}\left(\mathrm{~L}^{6}\right)_{10}\left(\mathbf{L n}_{4}, \mathbf{L n}=\right.$ $\mathrm{Gd}, \mathrm{Eu})$, and $\mathrm{Ln}_{6}\left(\mu_{3}-\mathrm{OH}\right)_{6}\left(\mathrm{~L}^{6}\right)_{12}\left(\mathbf{L n}_{6}, \mathrm{Ln}=\mathrm{Y}, \mathrm{Er}\right)$ for selective hydroboration (Figure 8) [56]. The hydroboration of $\mathrm{N}, \mathrm{N}$-dimethylbenzamide with pinacolborane (HBpin) catalyzed by $1.5 \mathrm{~mol} \%$ of $\mathbf{L a}_{4}$ afforded the targeted amine product in $95 \%$ yield. High tolerance for a great variety of substrates was subsequently established. In the meantime, the reduction of easter catalyzed by $\mathbf{L a}_{4}$ led to alcohol products with concomitant C-O cleavage. A preliminary mechanism study of its kinetic behavior and intermediate through initial rates studies and NMR spectra was preformed, respectively. The unique catalytic properties for the deoxygenation of $1^{\circ}$ carboxamides and esters are stimulating, which suggests the yet-to-be explored catalytic potentials of LOCs. The profound dependence of the cluster structure on the nature of the Ln ions offers another dimension of research on which many new catalytic applications of LOCs may be anticipated [21].

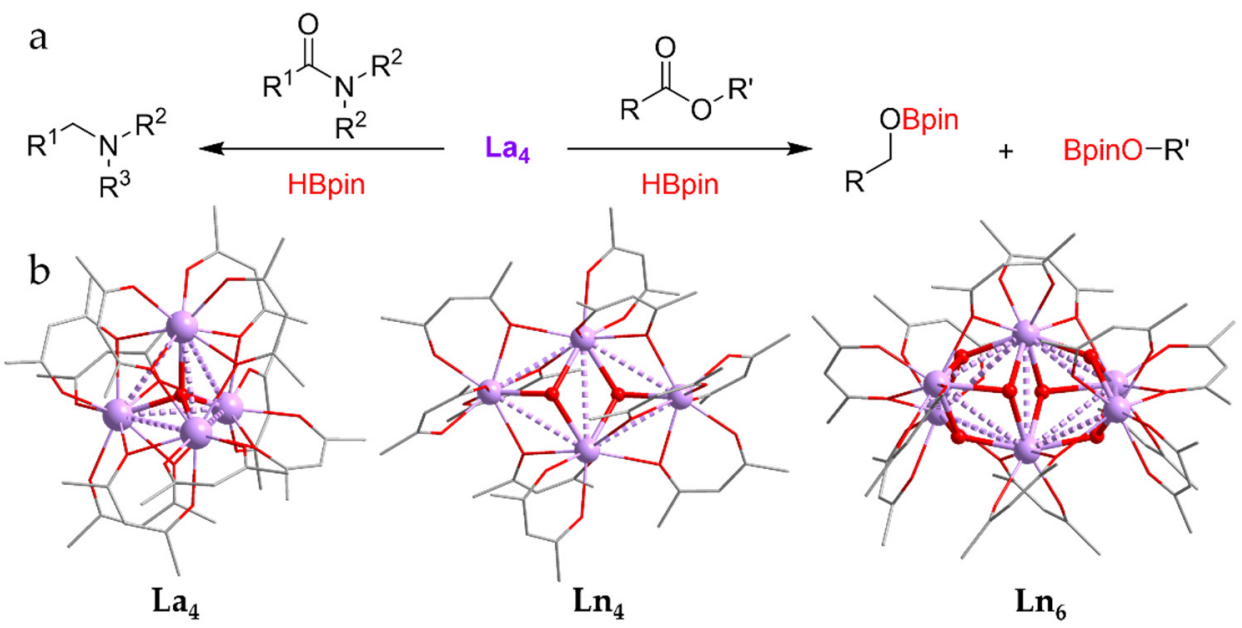

Figure 8. (a) The reduction of esters and carboxamides $\left(1^{\circ}, 2^{\circ}\right.$ and $\left.3^{\circ}\right)$ with catalyst of $\mathbf{L a}_{4}$. (b) The structures of $\mathbf{L a}_{\mathbf{4}}, \mathbf{L n}_{\mathbf{4}}$, and $\mathbf{L n}_{\mathbf{6}}$, respectively. Color legends: Ln, lavender; O, red; C, gray [56]. 


\section{Conclusions and Perspectives}

In this mini-review, the recent advances in the catalytic applications of LOCs with exclusive Ln ions or coexisting $3 d$ metal ions are surveyed. Although small in number, selective examples of LOCs for specific types of reaction catalyzed including chemical, electrochemical, and photochemical transformation of $\mathrm{CO}_{2}$ into value-added products, conversion, water oxidation, and hydrogen production in the overall scheme of water splitting, and hydroboration reaction to generate synthetically valuable products such as amines and alcohols are discussed. The results presently available in the literature portend the great catalytic potential of this unique family of Ln-containing species.

Future research efforts should probably be directed toward (1) the preparation and characterization of LOCs with sufficient stability in solution; (2) studies that may reveal mechanistic details of intermediate formation, the identification of the active sites, and any possible synergy between the component metals within the same LOC cluster core; and (3) catalytically capable LOCs with special structural features for efficient and selective catalysis. For example, clusters with cage-like structures characterized with accessible pores may be useful for stereospecific catalysis with enhanced reaction kinetics [23].

Author Contributions: Conceptualization, Z.Z.; investigation, W.H.; writing-original draft preparation, W.H.; writing-review and editing, M.F., W.C. and Z.Z.; visualization, Q.L.; supervision, Z.Z.; project administration, M.F.; funding acquisition, Z.Z. All authors have read and agreed to the published version of the manuscript.

Funding: This work was supported by the National Natural Science Foundation of China (no. 21971106), the Shenzhen Nobel Prize Scientists Laboratory Project (C17783101), Distinguished Expert Fund from Nanshan District of Shenzhen (K19219502), the Stable Support Project of Key Research Plan of Shenzhen, startup fund from SUSTech (Y01216127, Y01216227), Post-doctorate Scientific Research Fund for staying (coming to) Shenzhen (K21217521, K21217512).

Conflicts of Interest: The authors declare no conflict of interest.

\section{References}

1. Zheng, Y.-Z.; Zhou, G.-J.; Zheng, Z.; Winpenny, R.E.P. Molecule-based magnetic coolers. Chem. Soc. Rev. 2014, $43,1462-1475$. [CrossRef]

2. Shi, D.; Yang, X.; Chen, H.; Jiang, D.; Liu, J.; Ma, Y.; Schipper, D.; Jones, R.A. Large Ln $_{42}$ coordination nanorings: NIR luminescence sensing of metal ions and nitro explosives. Chem. Commun. 2019, 55, 13116-13119. [CrossRef]

3. Wagner, A.T.; Roesky, P.W. Rare-Earth Metal Oxo/Hydroxo Clusters-Synthesis, Structures, and Applications. Eur. J. Inorg. Chem. 2016, 2016, 782-791. [CrossRef]

4. Plakatouras, J.C.; Baxter, I.; Hursthouse, M.B.; Malik, K.M.A.; McAleese, J.; Drake, S.R. Synthesis and structural characterisation of two novel $\mathrm{Gd} \beta$-diketonates $\left[\mathrm{Gd}_{4}\left(\mu_{3}-\mathrm{OH}\right)_{4}\left(\mu_{2}-\mathrm{H}_{2} \mathrm{O}\right)_{2}\left(\mathrm{H}_{2} \mathrm{O}\right)_{4}(\mathrm{hfpd})_{8}\right] \cdot 2 \mathrm{C}_{6} \mathrm{H}_{6} \cdot \mathrm{H}_{2} \mathrm{O} 1$ and $\left[\mathrm{Gd}(\mathrm{hfpd})_{3}(\mathrm{Me} 2 \mathrm{CO})\left(\mathrm{H}_{2} \mathrm{O}\right)\right] 2(\mathrm{hfpd}-\mathrm{H}$ = 1,1,1,5,5,5-hexafluoropentane-2,4-dione). J. Chem. Soc. Chem. Commun. 1994, 1994, 2455-2456. [CrossRef]

5. Wang, R.; Zheng, Z.; Jin, T.; Staples, R.J. Coordination Chemistry of Lanthanides at "High" pH: Synthesis and Structure of the Pentadecanuclear Complex of Europium(III) with Tyrosine. Angew. Chem. Int. Ed. 1999, 38, 1813-1815. [CrossRef]

6. Zhang, J.-J.; Sheng, T.-L.; Xia, S.-Q.; Leibeling, G.; Meyer, F.; Hu, S.-M.; Fu, R.-B.; Xiang, S.-C.; Wu, X.-T. Syntheses and Characterizations of a Series of Novel $\mathrm{Ln}_{6} \mathrm{Cu}_{24}$ Clusters with Amino Acids as Ligands. Inorg. Chem. 2004, 43, 5472-5478. [CrossRef] [PubMed]

7. Kong, X.-J.; Ren, Y.-P.; Chen, W.-X.; Long, L.-S.; Zheng, Z.; Huang, R.-B.; Zheng, L.-S. A Four-Shell, Nesting Doll-like 3d-4f Cluster Containing 108 Metal Ions. Angew. Chem. Int. Ed. 2008, 47, 2398-2401. [CrossRef] [PubMed]

8. Zheng, X.-Y.; Kong, X.-J.; Zheng, Z.; Long, L.-S.; Zheng, L.-S. High-Nuclearity Lanthanide-Containing Clusters as Potential Molecular Magnetic Coolers. Acc. Chem. Res. 2018, 51, 517-525. [CrossRef]

9. Liu, J.-L.; Chen, Y.-C.; Guo, F.-S.; Tong, M.-L. Recent advances in the design of magnetic molecules for use as cryogenic magnetic coolants. Coord. Chem. Rev. 2014, 281, 26-49. [CrossRef]

10. Luo, X.-M.; Hu, Z.-B.; Lin, Q.-F.; Cheng, W.; Cao, J.-P.; Cui, C.-H.; Mei, H.; Song, Y.; Xu, Y. Exploring the Performance Improvement of Magnetocaloric Effect Based Gd-Exclusive Cluster Gd 60 . J. Am. Chem. Soc. 2018, 140, 11219-11222. [CrossRef]

11. Qin, L.; Zhou, G.-J.; Yu, Y.-Z.; Nojiri, H.; Schröder, C.; Winpenny, R.E.P.; Zheng, Y.-Z. Topological Self-Assembly of Highly Symmetric Lanthanide Clusters: A Magnetic Study of Exchange-Coupling "Fingerprints" in Giant Gadolinium(III) Cages. J. Am. Chem. Soc. 2017, 139, 16405-16411. [CrossRef] [PubMed]

12. Arnold, P.L.; McMullon, M.W.; Rieb, J.; Kühn, F.E. C-H Bond Activation by f-Block Complexes. Angew. Chem. Int. Ed. 2015, 54, 82-100. [CrossRef] 
13. Aguirre-Díaz, L.M.; Snejko, N.; Iglesias, M.; Sánchez, F.; Gutiérrez-Puebla, E.; Monge, M.Á. Efficient Rare-Earth-Based Coordination Polymers as Green Photocatalysts for the Synthesis of Imines at Room Temperature. Inorg. Chem. 2018, 57, 6883-6892. [CrossRef]

14. Alzamly, A.; Bakiro, M.; Hussein Ahmed, S.; Alnaqbi, M.A.; Nguyen, H.L. Rare-earth metal-organic frameworks as advanced catalytic platforms for organic synthesis. Coord. Chem. Rev. 2020, 425, 213543. [CrossRef]

15. Chen, X.; Xu, J.; Xu, Y.; Luo, F.; Du, Y. Rare earth double perovskites: A fertile soil in the field of perovskite oxides. Inorg. Chem. Front. 2019, 6, 2226-2238. [CrossRef]

16. Trovarelli, A. Catalytic properties of ceria and $\mathrm{CeO}_{2}$-containing materials. Catal. Rev. 1996, 38, 439-520. [CrossRef]

17. Qiao, Y.; Schelter, E.J. Lanthanide Photocatalysis. Acc. Chem. Res. 2018, 51, 2926-2936. [CrossRef] [PubMed]

18. Li, Y.; Marks, T.J. Organolanthanide-Catalyzed Intramolecular Hydroamination/Cyclization of Aminoalkynes. J. Am. Chem. Soc. 1996, 118, 9295-9306. [CrossRef]

19. Zheng, Z. Ligand-controlled self-assembly of polynuclear lanthanide-oxo/hydroxo complexes: From synthetic serendipity to rational supramolecular design. Chem. Commun. 2001, 2001, 2521-2529. [CrossRef]

20. Wang, R.; Selby, H.D.; Liu, H.; Carducci, M.D.; Jin, T.; Zheng, Z.; Anthis, J.W.; Staples, R.J. Halide-Templated Assembly of Polynuclear Lanthanide-Hydroxo Complexes. Inorg. Chem. 2002, 41, 278-286. [CrossRef]

21. Huang, W.; Zhang, Z.; Wu, Y.; Chen, W.; Rotsch, D.A.; Messerle, L.; Zheng, Z. A systematic study of halide-template effects in the assembly of lanthanide hydroxide cluster complexes with histidine. Inorg. Chem. Front. 2021, 8, 26-34. [CrossRef]

22. Zhou, G.-J.; Chen, W.-P.; Yu, Y.; Qin, L.; Han, T.; Zheng, Y.-Z. Filling the Missing Links of M 3 n Prototype 3d-4f and 4f Cyclic Coordination Cages: Syntheses, Structures, and Magnetic Properties of the $\mathrm{Ni}_{10} \mathrm{Ln}_{5}$ and the $\mathrm{Er}_{3 \mathrm{n}}$ Wheels. Inorg. Chem. 2017, 56, 12821-12829. [CrossRef]

23. Du, M.-H.; Zheng, X.-Y.; Kong, X.-J.; Long, L.-S.; Zheng, L.-S. Synthetic Protocol for Assembling Giant Heterometallic Hydroxide Clusters from Building Blocks: Rational Design and Efficient Synthesis. Matter 2020, 3, 1334-1349. [CrossRef]

24. Fan, S.; Xu, S.-H.; Zheng, X.-Y.; Yan, Z.-H.; Kong, X.-J.; Long, L.-S.; Zheng, L.-S. Four 3d-4f heterometallic Ln ${ }_{45} \mathrm{M}_{7}$ clusters protected by mixed ligands. CrystEngComm 2018, 20, 2120-2125. [CrossRef]

25. Zheng, X.-Y.; Peng, J.-B.; Kong, X.-J.; Long, L.-S.; Zheng, L.-S. Mixed-anion templated cage-like lanthanide clusters: Gd 27 and Dy27. Inorg. Chem. Front. 2016, 3, 320-325. [CrossRef]

26. Chen, W.-P.; Liao, P.-Q.; Jin, P.-B.; Zhang, L.; Ling, B.-K.; Wang, S.-C.; Chan, Y.-T.; Chen, X.-M.; Zheng, Y.-Z. The Gigantic $\mathrm{Ni}_{36} \mathrm{Gd}_{102}$ Hexagon: A Sulfate-Templated "Star-of-David" for Photocatalytic $\mathrm{CO}_{2}$ Reduction and Magnetic Cooling. J. Am. Chem. Soc. 2020, 142, 4663-4670. [CrossRef]

27. Zheng, X.-Y.; Jiang, Y.-H.; Zhuang, G.-L.; Liu, D.-P.; Liao, H.-G.; Kong, X.-J.; Long, L.-S.; Zheng, L.-S. A Gigantic Molecular Wheel of $\mathrm{Gd}_{140}$ : A New Member of the Molecular Wheel Family. J. Am. Chem. Soc. 2017, 139, 18178-18181. [CrossRef] [PubMed]

28. Pescarmona, P.P.; Taherimehr, M. Challenges in the catalytic synthesis of cyclic and polymeric carbonates from epoxides and $\mathrm{CO}_{2}$. Catal. Sci. Technol. 2012, 2, 2169-2187. [CrossRef]

29. Sakakura, T.; Choi, J.-C.; Yasuda, H. Transformation of Carbon Dioxide. Chem. Rev. 2007, 107, 2365-2387. [CrossRef] [PubMed]

30. Dong, J.; Cui, P.; Shi, P.-F.; Cheng, P.; Zhao, B. Ultrastrong Alkali-Resisting Lanthanide-Zeolites Assembled by [Ln 60 ] Nanocages. J. Am. Chem. Soc. 2015, 137, 15988-15991. [CrossRef] [PubMed]

31. Sinchow, M.; Semakul, N.; Konno, T.; Rujiwatra, A. Lanthanide Coordination Polymers through Design for Exceptional Catalytic Performances in $\mathrm{CO}_{2}$ Cycloaddition Reactions. ACS Sustain. Chem. Eng. 2021, 9, 8581-8591. [CrossRef]

32. Wei, N.; Zhang, Y.; Liu, L.; Han, Z.-B.; Yuan, D.-Q. Pentanuclear Yb(III) cluster-based metal-organic frameworks as heterogeneous catalysts for $\mathrm{CO}_{2}$ conversion. Appl. Catal. B-Environ. 2017, 219, 603-610. [CrossRef]

33. Zhang, R.; Wang, L.; Xu, C.; Yang, H.; Chen, W.; Gao, G.; Liu, W. Anion-induced 3d-4f luminescent coordination clusters: Structural characteristics and chemical fixation of $\mathrm{CO}_{2}$ under mild conditions. Dalton Trans. 2018, 47, 7159-7165. [CrossRef]

34. Wang, L.; Xu, C.; Han, Q.; Tang, X.; Zhou, P.; Zhang, R.; Gao, G.; Xu, B.; Qin, W.; Liu, W. Ambient chemical fixation of CO 2 using a highly efficient heterometallic helicate catalyst system. Chem. Commun. 2018, 54, 2212-2215. [CrossRef] [PubMed]

35. Qin, J.; Xu, B.; Zhang, Y.; Yuan, D.; Yao, Y. Cooperative rare earth metal-zinc based heterometallic catalysts for copolymerization of $\mathrm{CO}_{2}$ and cyclohexene oxide. Green Chem. 2016, 18, 4270-4275. [CrossRef]

36. Fukuzumi, S.; Lee, Y.-M.; Ahn, H.S.; Nam, W. Mechanisms of catalytic reduction of $\mathrm{CO}_{2}$ with heme and nonheme metal complexes. Chem. Sci. 2018, 9, 6017-6034. [CrossRef]

37. Wu, J.; Huang, Y.; Ye, W.; Li, Y. $\mathrm{CO}_{2}$ Reduction: From the Electrochemical to Photochemical Approach. Adv. Sci. 2017, 4, 1700194. [CrossRef] [PubMed]

38. Kojima, T. Photocatalytic Carbon Dioxide Reduction Using Nickel Complexes as Catalysts. ChemPhotoChem 2021, 5, 512-520. [CrossRef]

39. Ouyang, T.; Huang, H.-H.; Wang, J.-W.; Zhong, D.-C.; Lu, T.-B. A Dinuclear Cobalt Cryptate as a Homogeneous Photocatalyst for Highly Selective and Efficient Visible-Light Driven $\mathrm{CO}_{2}$ Reduction to $\mathrm{CO}$ in $\mathrm{CH}_{3} \mathrm{CN} / \mathrm{H}_{2} \mathrm{O}$ Solution. Angew. Chem. Int. Ed. 2017, 56, 738-743. [CrossRef] [PubMed]

40. Hong, D.; Kawanishi, T.; Tsukakoshi, Y.; Kotani, H.; Ishizuka, T.; Kojima, T. Efficient Photocatalytic $\mathrm{CO}_{2}$ Reduction by a Ni(II) Complex Having Pyridine Pendants through Capturing a $\mathrm{Mg}^{2+}$ Ion as a Lewis-Acid Cocatalyst. J. Am. Chem. Soc. 2019, 141, 20309-20317. [CrossRef] [PubMed] 
41. Zhang, L.-H.; Mathew, S.; Hessels, J.; Reek, J.N.H.; Yu, F. Homogeneous Catalysts Based on First-Row Transition-Metals for Electrochemical Water Oxidation. ChemSusChem 2021, 14, 234-250. [CrossRef]

42. Duan, L.; Wang, L.; Li, F.; Li, F.; Sun, L. Highly Efficient Bioinspired Molecular Ru Water Oxidation Catalysts with Negatively Charged Backbone Ligands. Acc. Chem. Res. 2015, 48, 2084-2096. [CrossRef] [PubMed]

43. Li, P.; Zhao, R.; Chen, H.; Wang, H.; Wei, P.; Huang, H.; Liu, Q.; Li, T.; Shi, X.; Zhang, Y.; et al. Recent Advances in the Development of Water Oxidation Electrocatalysts at Mild pH. Small 2019, 15, 1805103. [CrossRef]

44. Chen, R.; Chen, C.-L.; Du, M.-H.; Wang, X.; Wang, C.; Long, L.-S.; Kong, X.-J.; Zheng, L.-S. Soluble lanthanide-transition-metal clusters $\mathrm{Ln}_{36} \mathrm{Co}_{12}$ as effective molecular electrocatalysts for water oxidation. Chem. Commun. 2021, 57, 3611-3614. [CrossRef] [PubMed]

45. Lu, D.-F.; Kong, X.-J.; Lu, T.-B.; Long, L.-S.; Zheng, L.-S. Heterometallic Lanthanide-Titanium Oxo Clusters: A New Family of Water Oxidation Catalysts. Inorg. Chem. 2017, 56, 1057-1060. [CrossRef] [PubMed]

46. Fujishima, A.; Honda, K. Electrochemical Photolysis of Water at a Semiconductor Electrode. Nature 1972, 238, 37-38. [CrossRef] [PubMed]

47. Sun, D.; Li, Z. Robust Ti- and Zr-Based Metal-Organic Frameworks for Photocatalysis. Chin. J. Chem. 2017, 35, 135-147. [CrossRef]

48. Liu, G.; Zhao, Y.; Yao, R.; Li, N.; Wang, M.; Ren, H.; Li, J.; Zhao, C. Realizing high performance solar water oxidation for Ti-doped hematite nanoarrays by synergistic decoration with ultrathin cobalt-iron phosphate nanolayers. Chem. Eng. J. 2019, 355, 49-57. [CrossRef]

49. Lee, S.-Y.; Park, S.-J. $\mathrm{TiO}_{2}$ photocatalyst for water treatment applications. J. Ind. Eng. Chem. 2013, 19, 1761-1769. [CrossRef]

50. Miyoshi, A.; Nishioka, S.; Maeda, K. Water Splitting on Rutile $\mathrm{TiO}_{2}$-Based Photocatalysts. Chem. Eur. J. 2018, $24,18204-18219$. [CrossRef]

51. Yuan, Y.-J.; Chen, D.; Yu, Z.-T.; Zou, Z.-G. Cadmium sulfide-based nanomaterials for photocatalytic hydrogen production. J. Mater. Chem. A 2018, 6, 11606-11630. [CrossRef]

52. Shen, R.; Ren, D.; Ding, Y.; Guan, Y.; Ng, Y.H.; Zhang, P.; Li, X. Nanostructured CdS for efficient photocatalytic $\mathrm{H}_{2}$ evolution: A review. Sci. China Mater. 2020, 63, 2153-2188. [CrossRef]

53. Luo, W.; Liu, Y.; Chen, X. Lanthanide-doped semiconductor nanocrystals: Electronic structures and optical properties. Sci. China Mater. 2015, 58, 819-850. [CrossRef]

54. Chen, R.; Yan, Z.-H.; Kong, X.-J.; Long, L.-S.; Zheng, L.-S. Integration of Lanthanide-Transition-Metal Clusters onto CdS Surfaces for Photocatalytic Hydrogen Evolution. Angew. Chem. Int. Ed. 2018, 57, 16796-16800. [CrossRef] [PubMed]

55. Liu, H.; Eisen, M.S. Organo-f-Complexes for Efficient and Selective Hydroborations. Synthesis 2020, 52, 629-644. [CrossRef]

56. Tamang, S.R.; Singh, A.; Bedi, D.; Bazkiaei, A.R.; Warner, A.A.; Glogau, K.; McDonald, C.; Unruh, D.K.; Findlater, M. Polynuclear lanthanide-diketonato clusters for the catalytic hydroboration of carboxamides and esters. Nat. Catal. 2020, 3, 154-162. [CrossRef] 